\title{
Quantified Self-Using Consumer Wearable Device: Predicting Physical and Mental Health
}

\author{
Bens Pardamean ${ }^{1,2}$, Haryono Soeparno ${ }^{1,2}$, Arif Budiarto ${ }^{2,3}$, Bharuno Mahesworo ${ }^{2}$, James Baurley ${ }^{2}$ \\ ${ }^{1}$ Computer Science Department, BINUS Graduate Program - Master of Computer Science Program, Bina Nusantara University, Jakarta, Indonesia \\ ${ }^{2}$ Bioinformatics and Data Science Research Center, Bina Nusantara University, Jakarta, Indonesia \\ ${ }^{3}$ Computer Science Department, School of Computer Science, Bina Nusantara University, Jakarta, Indonesia
}

Objectives: Recently, wearable device technology has gained more popularity in supporting a healthy lifestyle. Hence, researchers have begun to put significant efforts into studying the direct and indirect benefits of wearable devices for health and wellbeing. This paper summarizes recent studies on the use of consumer wearable devices to improve physical activity, mental health, and health consciousness. Methods: A thorough literature search was performed from several reputable databases, such as PubMed, Scopus, ScienceDirect, arXiv, and bioRxiv mainly using "wearable device research" as a keyword, no earlier than 2018. As a result, 25 of the most recent and relevant papers included in this review cover several topics, such as previous literature reviews ( 9 papers), wearable device accuracy (3 papers), self-reported data collection tools ( 3 papers), and wearable device intervention (10 papers). Results: All the chosen studies are discussed based on the wearable device used, complementary data, study design, and data processing method. All these previous studies indicate that wearable devices are used either to validate their benefits for general wellbeing or for more serious medical contexts, such as cardiovascular disorders and post-stroke treatment. Conclusions: Despite their huge potential for adoption in clinical settings, wearable device accuracy and validity remain the key challenge to be met. Some lessons learned and future projections, such as combining traditional study design with statistical and machine learning methods, are highlighted in this paper to provide a useful overview for other researchers carrying out similar research.

Keywords: Wearable Electronic Device, Fitness Tracker, Exercise, Mental Health, Medical Informatics

Submitted: October 8, 2019

Revised: March 12, 2020

Accepted: April 17, 2020

\section{Corresponding Author}

Arif Budiarto

Computer Science Department, School of Computer Science, Bina Nusantara University, Jakarta 11480, Indonesia. Tel: +62-812-18035608, E-mail: abudiarto@binus.edu (https://orcid.org/0000-00018875-6694)

This is an Open Access article distributed under the terms of the Creative Commons Attribution Non-Commercial License (http://creativecommons.org/licenses/bync/4.0/) which permits unrestricted non-commercial use, distribution, and reproduction in any medium, provided the original work is properly cited.

(c) 2020 The Korean Society of Medical Informatics

\section{Introduction}

One way to keep track of the human body's most basic functions is by checking its vital signs, which includes body temperature, heart rate, respiration rate, and blood pressure. These variables can be monitored using wearable devices. Currently, wearable devices are on their way to their golden era. For the last couple of years, the market value of wearables has gradually climbed. The total shipment of wearable devices, including smartwatches, wrist bands, and ear-worn devices, climbed from 45.1 million units in 2017 to 59.3 million in 2018 [1]. Apple had the highest shipment volume, followed by Xiaomi, Huawei, Fitbit, and Samsung. However, Apple's shipments comprised AirPods and Beats headphones 
in the ear-worn category.

With various powerful wearable devices commercially available, there is still a lack of supporting applications that use these data to score the user's overall wellbeing, which includes physical health and psychological health. Along with physical health and psychological health scores, suggestions based on these data can be created to improve users' overall health and life quality. Researchers from several institutions have put significant efforts into studying the effects of wearable devices on health and wellbeing.

Lifelogging, also called quantified self (QS) is a dedicated action toward gathering, monitoring, recording, and measuring information of an individual's behaviors, biological function, physical, or environmental data, and acknowledging the information. In other words, QS is a self-tracking activity with actions toward the data. The term QS was first introduced by Wolf and Kelly [2] in the QS blog. The objective of this activity is to assess the individual's physical and psychological health level. Using the individual's behaviors, biological functions, and physical and environmental data as well as their health level, advice can be created to improve their health and life quality.

As technologies become more accessible, other measurable variables from different area of interest are increasing simultaneously. According to several studies [3,4], areas that are often used in QS are physical activities, diet, psychological states and traits, mental and cognitive states and traits, environmental variables, situational variables, and social variables.

This review paper aims to summarize the progress of research on consumer wearable device intervention in assessing physical and psychological health. First, we began this review by studying previous review papers to see the general trends of current wearable device research. As background, we provide a general overview of QS before comparing the latest relevant studies. We review the previous studies from three points of view: (1) data collection tools including wearable device accuracy, (2) self-reported data collection, and (3) study design and data processing.

\section{Methods}

A systematic literature search was performed in several wellknown databases related to computer science and health science, such as PMC, Scopus, ScienceDirect, arXiv, and bioRxiv. "Wearable device research" was used as the main keyword in this literature search to limit the search area. At first, there were more than 3,000 papers queried from all databases. A quick skimming of the title and abstracts of each article was conducted to exclude irrelevant articles that focused more on technical details and hardware rather than the use of this technology for intervention. This selection process was also done to remove duplicate articles across all databases. After this initial screening, there were 209 research articles gathered; these included 41 articles from PMC, 41 articles from ScienceDirect, 79 articles from Scopus, 39 articles from arXiv, and 9 articles from bioRxiv. Finally, after a careful selection process that involved all parts of each article, only 25 research articles were included in a thorough review. These included 9 review papers, 3 wearable accuracy articles, 3 selfreported data collection tool articles, and 10 wearable device intervention research articles. The overall selection process is presented in Figure 1.

To review the selected papers, three important aspects were proposed to make a comparison of the findings from all studies. The first one is wearable device accuracy because it is still a major issue for researchers who want to employ this technology in their research. The next aspect is self-reported data collection tools. To yield better insights for patients and physicians, data captured by wearable devices is ideally complemented by other personal data that can only be manually logged by users or patients. Study design and data processing is the next important aspect covered in this paper to give an overview to readers regarding how previous studies have been conducted and analyzed.

\section{Results}

To identify the current trends in wearable device research, 9 of the latest review papers that were published no earlier than January 1, 2018 were selected as the basis of the whole review process. Three of them comprehensively assessed wearable device technology intervention for general physical activities [5-7], while the other six papers covered more specific topics, such as sports [8], work environments [9], disease-specific cases [10,11], accuracy [12], and machine learning implementation [13], as seen in Table 1. Based on this initial review, 16 studies were further assessed. Table 2 summarizes all these studies based on the year of publication, main objective, study design, and general outcomes or insights.

\section{Wearable Device Accuracy}

Wearable devices, such as smartwatches and fitness trackers, are a very convenient way to measure daily activity [14] Most of these devices contain movement-related sensors, 


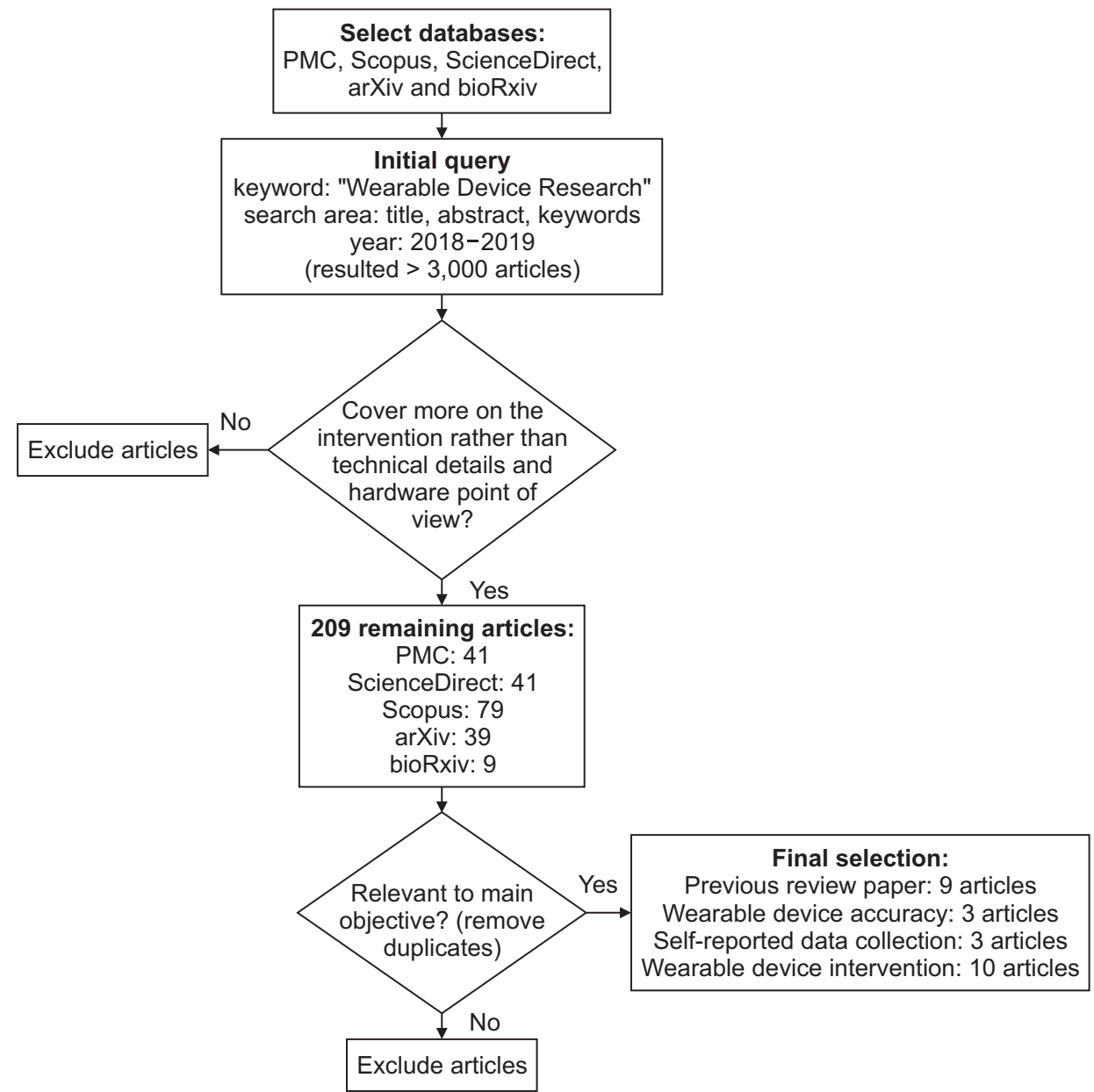

Figure 1. Literature search flow diagram.

Table 1. Summary of 9 recent review papers related to wearable device research

\begin{tabular}{|c|c|c|}
\hline Study & Year & Main topic \\
\hline Strath and Rowley [5] & 2018 & $\begin{array}{l}\text { The effect of consumer wearable device intervention on behavioral change, physical activity, and } \\
\text { health outcomes. }\end{array}$ \\
\hline Brickwood et al. [6] & 2019 & $\begin{array}{l}\text { The influences of consumer-based wearable activity tracker utilization on physical activity } \\
\text { participation and sedentary behavior. }\end{array}$ \\
\hline Bohm et al. [7] & 2019 & $\begin{array}{l}\text { The effects of the combination of mobile health technology and wearable activity tracker } \\
\text { intervention on physical activity-related outcomes. }\end{array}$ \\
\hline Aroganam et al. [8] & 2019 & $\begin{array}{l}\text { The trends and projections for wearable technology in the consumer sports sector. The role of } \\
\text { wearable technology for different users and its benefits in everyday lives. }\end{array}$ \\
\hline Khakurel et al. [9] & 2018 & $\begin{array}{l}\text { Current knowledge about the recent trends in wearable technology to assess both its potential in } \\
\text { the work environment and the challenges concerning the utilization of wearables in the workplace. }\end{array}$ \\
\hline Taj-Eldin et al. [10] & 2018 & $\begin{array}{l}\text { The benefits of wearable technology for certain populations who experience rapidly changing } \\
\text { emotional states, such as people with autism spectrum disorder and people with intellectual disabilities. }\end{array}$ \\
\hline Johansson et al. [11] & 2018 & $\begin{array}{l}\text { Quantitative and qualitative clinical research using wearable sensors in epilepsy, Parkinson's } \\
\text { disease, and stroke. }\end{array}$ \\
\hline Feehan et al. [12] & 2018 & The accuracy of Fitbit devices in clinical and research settings. \\
\hline Farrahi et al. [13] & 2019 & Machine learning approaches for validating and analyzing wearable device data. \\
\hline
\end{tabular}


Table 2. Summary of 16 recent studies related to wearable device research

\begin{tabular}{|c|c|c|c|}
\hline Study & Year & Main objective & Study design \\
\hline $\begin{array}{l}\text { Nelson and } \\
\text { Allen [15] }\end{array}$ & 2019 & $\begin{array}{l}\text { Assess the accuracy of the two most commonly used wearable } \\
\text { devices, Apple Watch } 3 \text { and Fitbit Charge 2, in measuring heart rate. }\end{array}$ & $\begin{array}{l}\text { 24-hour single-subject } \\
\text { observational study. }\end{array}$ \\
\hline $\begin{array}{l}\text { Witte et al. } \\
\text { [16] }\end{array}$ & 2019 & $\begin{array}{l}\text { Compare the accuracy of } 15 \text { commercial wearable devices in } \\
\text { measuring heart rate, step counts, and sleep duration. }\end{array}$ & $\begin{array}{l}\text { Observational study with } 6 \\
\text { healthy participants. }\end{array}$ \\
\hline $\begin{array}{l}\text { Kwon et al. } \\
{[17]}\end{array}$ & 2019 & $\begin{array}{l}\text { Estimating maximal oxygen uptake from daily activity data } \\
\text { measured by a watch-type fitness tracker: cross-sectional study. }\end{array}$ & $\begin{array}{l}\text { Exploratory study. Statistical } \\
\text { learning implementation. }\end{array}$ \\
\hline $\begin{array}{l}\text { Jang et al. } \\
\text { [22] }\end{array}$ & 2018 & $\begin{array}{l}\text { Evaluate the impact of wearable device and mobile app intervention } \\
\text { towards general health outcomes of older adults in rural areas. }\end{array}$ & $\begin{array}{l}\text { Pre-post trial with } 22 \\
\text { participants. }\end{array}$ \\
\hline $\begin{array}{l}\text { Stiglbaur } \\
\text { et al. [26] }\end{array}$ & 2019 & $\begin{array}{l}\text { Evaluate the influence of wearable self-tracking devices on consciousness, } \\
\text { physical health, and indicators of psychological wellbeing. }\end{array}$ & $\begin{array}{l}\text { Pre-post and case-control trial } \\
\text { with } 80 \text { participants. }\end{array}$ \\
\hline $\begin{array}{l}\text { Sano et al. } \\
\text { [27] }\end{array}$ & 2018 & $\begin{array}{l}\text { Identify objective physiological markers and modifiable behaviors for } \\
\text { self-reported stress and mental health status using wearable sensors } \\
\text { and mobile phones: observational study. }\end{array}$ & $\begin{array}{l}\text { Observational study with } 201 \\
\text { participants. } \\
\text { Machine learning algorithm } \\
\text { implementation study. }\end{array}$ \\
\hline $\begin{array}{l}\text { Compagnat } \\
\text { et al. [33] }\end{array}$ & 2019 & $\begin{array}{l}\text { Validate the reliability of wearable device accuracy and measure the } \\
\text { impact of various wearable positions in stroke patients. }\end{array}$ & $\begin{array}{l}\text { Randomized control trial with } \\
35 \text { participants. }\end{array}$ \\
\hline $\begin{array}{l}\text { Cheong } \\
\text { et al. [34] }\end{array}$ & 2018 & $\begin{array}{l}\text { Evaluate the impact of wearable device and mobile app intervention } \\
\text { on colorectal cancer patients undergoing chemotherapy. }\end{array}$ & $\begin{array}{l}\text { Pre-post trial with } 102 \\
\text { participants. }\end{array}$ \\
\hline $\begin{array}{l}\text { Lim et al. } \\
\text { [35] }\end{array}$ & 2018 & $\begin{array}{l}\text { Beyond fitness tracking: the use of consumer-grade wearable data } \\
\text { from normal volunteers in cardiovascular and lipidomics research. }\end{array}$ & $\begin{array}{l}\text { Exploratory study. Statistical } \\
\text { learning implementation. }\end{array}$ \\
\hline $\begin{array}{l}\text { Buchele } \\
\text { et al. [36] }\end{array}$ & 2018 & $\begin{array}{l}\text { Examine the effects of wearable device intervention on students' daily } \\
\text { physical activities and aerobic fitness levels. }\end{array}$ & $\begin{array}{l}\text { Pre-post and case-control trial } \\
\text { with } 116 \text { participants. }\end{array}$ \\
\hline $\begin{array}{l}\text { Reddy } \\
\text { et al. [37] }\end{array}$ & 2018 & $\begin{array}{l}\text { Validate the accuracy of Fitbit Charge } 2 \text { and Garmin Vivosmart HR+ } \\
\text { to measure heart rate and energy expenditure during a variety of } \\
\text { dynamic activities. }\end{array}$ & $\begin{array}{l}\text { Randomized trial with } 20 \\
\text { participants. }\end{array}$ \\
\hline $\begin{array}{l}\text { Vandelanotte } \\
\text { et al. [38] }\end{array}$ & 2018 & $\begin{array}{l}\text { Assess the effectiveness of a web-based computer-tailored physical } \\
\text { activity intervention using Fitbit activity trackers: randomized trial. }\end{array}$ & $\begin{array}{l}\text { Randomized pre-post case-con- } \\
\text { trol trial with } 243 \text { participants. }\end{array}$ \\
\hline $\begin{array}{l}\text { Jones et al. } \\
\text { [39] }\end{array}$ & 2018 & $\begin{array}{l}\text { Evaluate the accuracy of Fitbit Flex and ActiGraph GT3X+ to measure } \\
\text { step count during jogging and running speeds. }\end{array}$ & $\begin{array}{l}\text { Randomized control trial with } \\
30 \text { participants. }\end{array}$ \\
\hline $\begin{array}{l}\text { Redenius } \\
\text { et al. [40] }\end{array}$ & 2019 & $\begin{array}{l}\text { Compare the validity of Fitbit Flex and ActiGraph GT3X+ for } \\
\text { sedentary behavior and physical activity. }\end{array}$ & $\begin{array}{l}\text { Randomized control trial with } \\
65 \text { participants. }\end{array}$ \\
\hline $\begin{array}{l}\text { Collins } \\
\text { et al. [41] }\end{array}$ & 2019 & $\begin{array}{l}\text { Compare the accuracy of Fitbit Charge 2, wrist-worn ActiGraph } \\
\text { GT3X+, and hip-worn ActiGraph to measure physical activity and } \\
\text { sedentary time in knee osteoarthritis patients. }\end{array}$ & $\begin{array}{l}\text { Randomized control trial with } \\
35 \text { participants. }\end{array}$ \\
\hline $\begin{array}{l}\text { Varatharajan } \\
\text { et al. [46] }\end{array}$ & 2018 & $\begin{array}{l}\text { Measure foot movements of Alzheimer patients using a wearable } \\
\text { device. }\end{array}$ & $\begin{array}{l}\text { Machine learning algorithm } \\
\text { implementation study. }\end{array}$ \\
\hline
\end{tabular}

such as accelerometers, gyroscopes, global positioning systems, and compasses, to predict user movement and interpret the information as a daily step count, calorie burned, active time, exercise log, sleep time, and even sleep quality $[8,11]$. Other sensors are heart rate and environment-related sensors, such as barometer, altimeters, ambient light meters, and thermometers. Prior to selecting the wearable device that will be used in a study, careful precautions must be taken to avoid unwanted results related to measurement errors. One important factor usually considered in this process is the device's accuracy. This refers to the quality of a sensor's reading, which consequently affects the quality of the measured results.

Heart rate monitoring and step counting are two of the 
most important wearable device measurements commonly included in recent studies. A single-subject study conducted by Nelson and Allen [15] successfully evaluated the heart rate measurement of two of the most popular wearable devices on the market, Apple Watch 3 and Fitbit Charge 2. These two devices were worn for 24 hours to continuously measure a single subject's heart rate during five daily activities, namely, sitting, walking, running, daily living activities, and sleeping. Measurement results obtained by both devices were compared to measurement from a gold standard ambulatory electrocardiogram (ECG) as the ground-truth data. Both tested devices showed a generally accurate measurement compare to ECG measurement across all of the activities.

Another study demonstrated a promising finding regarding the accuracy of commercial wearable devices in measuring heart rate and step count [16]. In this study, 15 commercial wearable devices were tested to measure heart rate, step count, and sleep duration in 6 healthy participants. The authors designed various scenarios for all measurement variables. Surprisingly, Apple and Fitbit, as the most popular devices, were outperformed by other brands, such as TomTom and Huawei.

In addition to heart rate monitoring and step counts, wearable technology can also estimate cardiorespiratory fitness, which is usually represented by the $\mathrm{VO}_{2 \max }$ value, as a vital sign for individuals' health status using data gathered from the sensors. Recently, Kwon et al. [17] successfully conducted a cross-sectional study to develop a model that can estimate $\mathrm{VO}_{2 \max }$ values. They used a Fitbit product to collect a relatively large amount of daily activity data, especially heart rate, from 191 participants. They managed to address the inaccuracy issue of Fitbit measurement by developing a model that relies on the pattern of time-series data rather than depending on single data points.

\section{Self-Reporting Data Collection}

To complement data captured by wearable devices, a selfreport form is usually used to collect other relevant information from users. Usually, these data are used as the dependent variable. In general, these data can be divided into three groups: health awareness, physical health, and mental health.

\section{1) Health awareness}

Health awareness can be associated with behavior or habits that can influence the user's health status. Many studies have targeted several variables to measure health awareness changes in their participants, including exercising or physical activity duration and frequency, eating nutritious foods or diet, smoking and alcohol drinking habits $[18,19]$. These variables can represent the participants' willingness to develop a healthier lifestyle or behavior. Thus, by making health-related issues a subject of discussion and more salient in people's everyday lives, their health awareness should rise [20].

\section{2) Physical health}

As mentioned before, there have been many studies that have shown that QS technology can trigger health behavior change, such as physical activity that has a positive effect on people's health [21]. A study was conducted by Jang et al. [22] to evaluate the impact of wearable devices and mobilebased intermittent coaching to improve the physical health of their participants. The physical health of their participants was assessed using the usual gait speed, International Physical Activity Questionnaire (IPAQ) scores [23], and European Quality of Life-5 (EQ-5D-5L) Dimensions scores [24]. The IPAQ is a questionnaire consisting of four questions about health-related physical activity. On the other hand, the EQ$5 \mathrm{D}-5 \mathrm{~L}$ is a health assessment instrument that comprises five dimensions: mobility, self-care, usual activities, pain/discomfort, and anxiety/depression.

\section{3) Mental health}

Wearable device intervention can have advantages for physical health as well as mental health or psychological wellbeing, which associated with better life status. Stress, depression, and anxiety are some of the most common mental health problems for modern office workers. One of the most common measurement tools that can be used to assess a person's mental health is Perma Profiler. This questionnaire includes several points to describe someone's wellbeing status, including positive emotion, negative emotion, happiness, and loneliness [25]. Stiglbauer et al. [26], used this tool in their longitudinal study in validating the benefits of wearable intervention for human wellbeing. An earlier study conducted by Sano et al. [27], combined five different types of mental health measurement tools [28-32] to gather complementary data to support their observational study. Additionally, they also developed a web application as an ediary to capture daily data from participants.

\section{Study Design and Data Processing}

Planning a good study design is crucial to obtain highquality research results, especially when a group of people are involved as participants. Two types of study designs are 
usually applied in wearable-based research. The first type is case-control study, and the other is pre-post study. These two types of study designs involve specific interventions to be implemented either with a particular group or all samples; therefore, both study designs are very suitable for wearable device intervention research. However, observational study is also a possible alternative that can be adopted to assess the benefits of wearable devices in normal daily live. Each study design has its own advantages, depending on the research objectives. In addition to these general study designs, researchers have recently started to study machine learning implementation in processing wearable device data to detect or predict several vital signs and health problems. This section covers the elaboration of study design from the most recent wearable device research in two main groups, namely, studies on general health and wellbeing and disease-specific studies, including how researchers process and analyze the data.

\section{1) General health and wellbeing research}

The most recent research on wearable devices for general wellbeing using a pre-post design was done by Stiglbauer et al. [26]. The main objective of their research was to explore the potential benefits of wearable devices in affecting health and wellbeing. They did a longitudinal randomized control study to measure health consciousness, physical health, and indicators of psychological wellbeing as the dependent variables. After a thorough screening using their inclusionexclusion criteria, 25 participants were excluded out of 105 students. The selected participants were then asked to wear Xiaomi Mi Band 2 to track their activities for two weeks. A baseline questionnaire at the beginning of the study and an evaluation questionnaire at the end were compared to see the effect of wearing a fitness tracker on the previously mentioned dependent variables.

Another interesting study was conducted by Jang et al. [22], which focused only on elderly people in a rural area. The motivation of this study was to use technology intervention to support the subjects of the study to optimize their healthcare. In this 13-month pre-post study, the participants initially were given a 6 -month coaching program to use the wearable device, followed by a 1-month rest, and a 6-month self-management program. The researchers randomly recruited 22 participants, who were divided into two groups based on their frailty (robust and prefrail) with several inclusion criteria. From this study, a significant health improvement occurred in the prefrail group, indicated by the increase of usual gait speed, IPAQ scores [23], and EQ-5D-
5L Dimensions score [24]. To analyze the data, a non-parametric Mann-Whitney-Wilcoxon test and Fisher test were used because of the relatively small sample size. These tests were applied to compare mean from two different states, at the beginning of the program and the end of the program.

\section{2) Disease-specific research}

Besides the research exploring the effects of wearable devices on general human wellbeing, other research focused on specific diseases has also been done in recent years. The rapid advancement of wearable device technology provides an opportunity for physicians and researchers to design and monitor good treatments for patients. For instance, Compagnat et al. [33] recently published an exploratory research report on the utilization of wearable device in monitoring the walking habits of post-stroke patients. They recruited 35 individuals who had history of a single stroke that had been confirmed by brain imaging, the ability to walk for six minutes without the support of others, and no decompensated chronic pathologies. The main objective of this study was to validate the accuracy of wearable device measurement and to identify the best sensor position to obtain the most accurate measurement. The study concluded that to gain more accurate measurement, the best position of a wearable device for stroke patients is on either the unaffected ankle or hip.

One expectation of including wearable device intervention in a patient's treatment program is to yield good treatment adherence and thus to boost physical improvement. This motivation was the main background of one study conducted by Cheong et al. [34] to explore the benefits of wearable intervention in improving the physical performance of colorectal cancer patients after receiving chemotherapy treatment. In total there were 75 patients who were undergoing chemotherapy treatment included in this study. Patients were given a 12-week program that required them to wear Partron's Urban wearable device, which was complementary to a mobile application that recorded daily activities. To measure each patient's physical improvement, an IPAQ shortform was provided [23]. This study showed that there was an increase in physical activity in the patients six weeks after the beginning of the program. However, during the period between 6 to 12 weeks of the program, there was a decrease in physical activities. To compare the physical health states before and after the program, a paired $t$-test was applied.

Another promising study was performed by Lim et al. in which they implemented statistical and machine learning methods to explore the association of wearable device data, daily steps and resting heart rate (RHR), with clinical 
markers related to cardiovascular and metabolic disorders (CVMD) in 233 participants [35]. They found that both daily steps and RHR are significantly associated with clinical markers, such as systolic blood pressure, diastolic blood pressure, as well as fasting levels of total cholesterol, highdensity lipoprotein, low-density lipoprotein, and so forth. Their findings successfully validated the advantages and usefulness of wearable devices beyond the simple monitoring of daily activities.

\section{Discussion}

This paper is aimed to help researchers who want to conduct studies on wearable device interventions. Based on the lessons learned from previous research, in designing a good quality study that uses wearable device as the data collection tool, researchers need to consider four important factors, namely, effective study design, participant recruitment, wearable device selection, and data analysis strategy. The most crucial factor in an experimental study that involves participants is to plan an effective study design and protocol. Pre-post, case-control, and the combination of these two designs are the most frequently selected choices implemented by researchers. These two types of study designs are commonly used in medical research. Pre-post studies are usually conducted to evaluate whether the proposed program can make a positive contribution to improving the health, psychological wellbeing and health awareness of the participants. On the other hand, a case-control study allows researchers to examine the benefits of wearable devices in two different groups.

The next aspect is the participant recruitment strategy. Research frameworks as part of the study design can be a guideline for determining the number of participants and a strategy to recruit them. To recruit only appropriate participants, inclusion and exclusion criteria need to be defined. These criteria depend on the scope of the study. If the researchers target healthy people, then the most obvious inclusion criteria are that the participants must be in a good general health. For other studies, more inclusion and exclusion criteria might be needed to eliminate any potential bias that can lead to poor data analysis.

Researchers also need to decide the most appropriate wearable device to be used. From the aforementioned relevant research, the most popular consumer devices are Fitbit products [12,36-41]. Fitbit products achieve a higher accuracy than other consumer wearable devices. Accuracy is the main factor for researchers to choose Fitbit for their data collec- tion tools. However, other brands, such as Xiaomi Mi Band, offer more affordable cost for researcher to do a study with larger numbers of participants.

The most important aspect of wearable-based research is an effective and robust data analysis strategy. The use of wearable devices can generate a significant amount of data for researchers to analyze. Statistical methods are still the first choice because of their powerful and comprehensive analysis capability. A common type of hypothesis that needs to be proven is whether there are significant differences in two groups or two states. By using a statistical test, such as a paired $t$-test, Mann-Whitney-Wilcoxon test, or Fisher test, the comparison score between two means can be obtained $[22,34]$. Additionally, wearable device data can be analyzed in a more advanced machine learning framework, such as deep learning $[42,43]$. It can be framed as a prediction problem with the most common use case for elderly or sick people. Wearable data from a patient is processed as time series data to predict any critical condition of the patient, such as fall detection [44], heart disease [45], or even to detect early signs of Alzheimer disease [46].

In conclusion, in this review study, we selected relevant publications from reputable databases related to wearable device research. The main motivation behind this paper is to give an up-to-date general overview of current research and trends involving wearable device interventions to improve health and wellbeing. From all these previous studies, we identified several factors that should be considered by other researchers. The first is the study design, which will determine the research framework. Researchers can choose between pre-post and case-control study or a combination of both. The selected study design will affect the sample size, as will the participant recruitment strategy, which includes defining the inclusion and exclusion criteria. The next crucial factor is to choose the most appropriate wearable device, which mainly is based on budget. Although Fitbit is considered the most accurate and robust wearable, there are other less expensive devices. The last important key point is the opportunity to implement advanced machine learning methods in analyzing time-series data captured by wearable devices to predict several vital signs and markers related to specific disorders. Collecting massive wearable device data from a large cohort study and complement this data with important clinical markers, either from questionnaires or clinical measurements, can boost the performance of a prediction model, which consequently allows this model to be integrated into real clinical settings. 


\section{Conflict of Interest}

No potential conflict of interest relevant to this article was reported.

\section{Acknowledgments}

This study is funded by Directorate of Research and Community Service, Directorate General of Research and Development, Indonesian Ministry of Research, Technology and Higher Education as a part of 2019 Applied Excellent Research in Higher Education Grant.

\section{ORCID}

Bens Pardamean (http://orcid.org/0000-0002-7404-9005)

Haryono Soeparno (http://orcid.org/0000-0001-9766-0352)

Arif Budiarto (http://orcid.org/0000-0001-8875-6694)

Bharuno Mahesworo (http://orcid.org/0000-0003-1017-2917)

James Baurley (http://orcid.org/0000-0003-4116-7723)

\section{References}

1. IDC. IDC reports strong growth in the worldwide wearables market, led by holiday shipments of smartwatches, wrist bands, and ear-worn devices [Internet]. Framingham (MA): IDC Corporate; 2019 [cited at 2020 Apr 15]. Available from: https://www.idc.com/getdoc. jsp? containerId=prUS44901819.

2. Wolf G, Kelly K. What is Quantified Self? [Internet]. [place unknown]: Quantified Self; 2019 [cited at 2020 Apr 15]. Available from: https://quantifiedself.com/ about/what-is-quantified-self/.

3. Swan M. The Quantified Self: fundamental disruption in big data science and biological discovery. Big Data 2013;1(2):85-99.

4. Prince JD. The Quantified Self: operationalizing the quotidien. J Electron Resour Med Libr 2014;11(2):91-9.

5. Strath SJ, Rowley TW. Wearables for promoting physical activity. Clin Chem 2018;64(1):53-63.

6. Brickwood KJ, Watson G, O'Brien J, Williams AD. Consumer-based wearable activity trackers increase physical activity participation: systematic review and metaanalysis. JMIR Mhealth Uhealth 2019;7(4):e11819.

7. Bohm B, Karwiese SD, Bohm H, Oberhoffer R. Effects of mobile health including wearable activity trackers to increase physical activity outcomes among healthy children and adolescents: systematic review. JMIR Mhealth
Uhealth 2019;7(4):e8298.

8. Aroganam G, Manivannan N, Harrison D. Review on wearable technology sensors used in consumer sport applications. Sensors (Basel) 2019;19(9):1983.

9. Khakurel J, Melkas H, Porras J. Tapping into the wearable device revolution in the work environment: a systematic review. Inf Technol People 2018;31(3);791-818.

10. Taj-Eldin M, Ryan C, O'Flynn B, Galvin P. A review of wearable solutions for physiological and emotional monitoring for use by people with autism spectrum disorder and their caregivers. Sensors (Basel) 2018;18(12):4271.

11. Johansson D, Malmgren K, Alt Murphy M. Wearable sensors for clinical applications in epilepsy, Parkinson's disease, and stroke: a mixed-methods systematic review. J Neurol 2018;265(8):1740-52.

12. Feehan LM, Geldman J, Sayre EC, Park C, Ezzat AM, Yoo JY, et al. Accuracy of Fitbit devices: systematic review and narrative syntheses of quantitative data. JMIR Mhealth Uhealth 2018;6(8):e10527.

13. Farrahi V, Niemela M, Kangas M, Korpelainen R, Jamsa T. Calibration and validation of accelerometer-based activity monitors: a systematic review of machine-learning approaches. Gait Posture 2019;68:285-99.

14. Bloss R. Wearable sensors bring new benefits to continuous medical monitoring, real time physical activity assessment, baby monitoring and industrial applications. Sens Rev 2015;35(2);141-5.

15. Nelson BW, Allen NB. Accuracy of consumer wearable heart rate measurement during an ecologically valid 24-hour period: intraindividual validation study. JMIR Mhealth Uhealth 2019;7(3):e10828.

16. Witte AK, Blankenhagel KJ, Korbel JJ, Zarnekow R. How accurate is accurate enough? An evaluation of commercial fitness trackers for individual health management. Proceedings of the Americas Conference on Information Systems (AMCIS2019); 2019 Aug 15-17; Cancun, Mexico.

17. Kwon SB, Ahn JW, Lee SM, Lee J, Lee D, Hong J, et al. Estimating maximal oxygen uptake from daily activity data measured by a watch-type fitness tracker: cross-sectional study. JMIR Mhealth Uhealth 2019;7(6):e13327.

18. Dutta-Bergman MJ. Primary sources of health information: comparisons in the domain of health attitudes, health cognitions, and health behaviors. Health Commun 2004;16(3):273-88.

19. Holzinger A, Dorner S, Fodinger M, Valdez AC, Ziefle M. Chances of increasing youth health awareness through mobile wellness applications. In: Leitner G, 
Hitz M, Holzinger A, editors. HCI in work and learning, life and leisure. Heidelberg: Springer; 2010. p. 71-81.

20. Grifantini K. How's my sleep?: personal sleep trackers are gaining in popularity, but their accuracy is still open to debate. IEEE Pulse 2014;5(5):14-8.

21. Etkin J. The hidden cost of personal quantification. Journal of Consumer Research 2016;42(6):967-84.

22. Jang IY, Kim HR, Lee E, Jung HW, Park H, Cheon SH, et al. Impact of a wearable device-based walking programs in rural older adults on physical activity and health outcomes: cohort study. JMIR Mhealth Uhealth 2018;6(11): e11335.

23. Craig CL, Marshall AL, Sjostrom M, Bauman AE, Booth $\mathrm{ML}$, Ainsworth BE, et al. International physical activity questionnaire: 12-country reliability and validity. Med Sci Sports Exerc 2003;35(8):1381-95.

24. Rabin R, Gudex C, Selai C, Herdman M. From translation to version management: a history and review of methods for the cultural adaptation of the EuroQol fivedimensional questionnaire. Value Health 2014;17(1):706.

25. Butler J, Kern ML. The PERMA-Profiler: a brief multidimensional measure of flourishing. Intl J Wellbeing 2016;6(3):1-48.

26. Stiglbauer B, Weber S, Batinic B. Does your health really benefit from using a self-tracking device? Evidence from a longitudinal randomized control trial. Comput Human Behav 2019;94:131-9.

27. Sano A, Taylor S, McHill AW, Phillips AJ, Barger LK, Klerman $\mathrm{E}$, et al. Identifying objective physiological markers and modifiable behaviors for self-reported stress and mental health status using wearable sensors and mobile phones: observational study. J Med Internet Res 2018;20(6):e210.

28. Horne JA, Ostberg O. A self-assessment questionnaire to determine morningness-eveningness in human circadian rhythms. Int J Chronobiol 1976;4(2):97-110.

29. Buysse DJ, Reynolds CF 3rd, Monk TH, Berman SR, Kupfer DJ. The Pittsburgh Sleep Quality Index: a new instrument for psychiatric practice and research. Psychiatry Res 1989;28(2):193-213.

30. Cohen S, Kamarck T, Mermelstein R. A global measure of perceived stress. J Health Soc Behav 1983;24(4):38596.

31. Ware J Jr, Kosinski M, Keller SD. A 12-Item Short-Form Health Survey: construction of scales and preliminary tests of reliability and validity. Med Care 1996;34(3):22033.
32. John OP, Srivastava S. The Big Five trait taxonomy: history, measurement, and theoretical perspectives. In: Pervin LA, John OP, editors. Handbook of personality: theory and research. 2nd ed. New York (NY): The Guilford Press; 1999. p. 102-38.

33. Compagnat M, Batcho CS, David R, Vuillerme N, Salle JY, Daviet JC, et al. Validity of the walked distance estimated by wearable devices in stroke individuals. Sensors (Basel) 2019;19(11):2497.

34. Cheong IY, An SY, Cha WC, Rha MY, Kim ST, Chang DK, et al. Efficacy of mobile health care application and wearable device in improvement of physical performance in colorectal cancer patients undergoing chemotherapy. Clin Colorectal Cancer 2018;17(2):e353-e362.

35. Lim WK, Davila S, Teo JX, Yang C, Pua CJ, Blocker C, et al. Beyond fitness tracking: the use of consumer-grade wearable data from normal volunteers in cardiovascular and lipidomics research. PLoS Biol 2018;16(2):e2004285.

36. Buchele Harris H, Chen W. Technology-enhanced classroom activity breaks impacting children's physical activity and fitness. J Clin Med 2018;7(7):165.

37. Reddy RK, Pooni R, Zaharieva DP, Senf B, El Youssef J, Dassau E, et al. Accuracy of wrist-worn activity monitors during common daily physical activities and types of structured exercise: evaluation study. JMIR Mhealth Uhealth 2018;6(12):e10338.

38. Vandelanotte C, Duncan MJ, Maher CA, Schoeppe S, Rebar AL, Power DA, et al. The effectiveness of a webbased computer-tailored physical activity intervention using Fitbit activity trackers: randomized trial. J Med Internet Res 2018;20(12):e11321.

39. Jones D, Crossley K, Dascombe B, Hart HF, Kemp J. Validity and reliability of the Fitbit Flex and ActiGraph GT3X+ at jogging and running speeds. Int J Sports Phys Ther 2018;13(5):860-70.

40. Redenius N, Kim Y, Byun W. Concurrent validity of the Fitbit for assessing sedentary behavior and moderateto-vigorous physical activity. BMC Med Res Methodol 2019;19(1):29.

41. Collins JE, Yang HY, Trentadue TP, Gong Y, Losina E. Validation of the Fitbit Charge 2 compared to the ActiGraph GT3X+ in older adults with knee osteoarthritis in free-living conditions. PLoS One 2019;14(1):e0211231.

42. Ravi D, Wong C, Lo B, Yang GZ. A deep learning approach to on-node sensor data analytics for mobile or wearable devices. IEEE J Biomed Health Inform 2017; 21(1):56-64.

43. Bai J, Sun Y, Schrack JA, Crainiceanu CM, Wang MC. 
A two-stage model for wearable device data. Biometrics 2018;74(2):744-52.

44. de Quadros T, Lazzaretti AE, Schneider FK. A movement decomposition and machine learning-based fall detection system using wrist wearable device. IEEE Sens J 2018;18(12):5082-9.

45. Shashikumar SP, Shah AJ, Li Q, Clifford GD, Nemati S. A deep learning approach to monitoring and detecting atrial fibrillation using wearable technology. Proceedings of 2017 IEEE EMBS International Conference on Biomedical \& Health Informatics (BHI); 2017 Feb 1619; Orlando, FL. p. 141-4.

46. Varatharajan R, Manogaran G, Priyan MK, Sundarasekar R. Wearable sensor devices for early detection of Alzheimer disease using dynamic time warping algorithm. Cluster Comput 2018;21(1):681-90. 